\title{
Improved Human Thermal Comfort with Indoor PCM-Enhanced Tiles in Living Spaces in the Arabian Gulf
}

\author{
Albert Al Touma, Djamel Ouahrani \\ Department of Architecture and Urban Planning, College of Engineering, Qatar University, Doha, Qatar
}

\begin{abstract}
Al-Majlis is the living space in residential buildings of the Arabian Gulf, and is where occupants spend most of their time. For this reason, the human thermal comfort in this space is of extreme importance and is often compromised due to hot outdoor weather conditions. In contrast with many thermal discomfort mitigation methods in outdoor environments, which become unadvisable in indoor spaces, this study investigates the effect of adding PCM-enhanced tiles to portions of the indoor envelope on the occupant's thermal comfort and the space cooling energy demand. A simulation model of a space with tight building envelope in Qatar was developed on EnergyPlus with and without the addition of PCM-enhanced tiles. The selected country is a representative location of the Arabian Gulf. Considering different occupant's positions, the addition of the tiles with PCM on their back was found to moderate the mean radiant temperature, operative temperature, Predicted Mean Vote (PMV) and Predicted Percentage of Dissatisfied (PPD), all of which signify an improvement in the human thermal comfort. Lastly, this change in the indoor envelope was found to save $3.3 \%$ of the space daily thermal cooling energy demand during one harsh summer representative day.
\end{abstract}

\section{Introduction}

Energy consumption has been a hot research topic due to its increasing annual trend, fortunately at a decelerating rate [1]. Among the different energy-consuming sectors, buildings still account for over $40 \%$ of the annual energy consumption worldwide [2]. In the Arabian Gulf, this percentage is even higher. In fact, residential and commercial buildings consume around $65 \%$ of the total electricity produced in the Kingdom of Saudi Arabia [3] and over $60 \%$ of the total energy produced in Qatar [4]. In this region of the world, the living space of the residential buildings, or the so-called Al-Majlis, is of unique importance as it accounts for a significant contributive share.

Al-Majlis is a unique thermal zone in almost each residential building in the Arabian Gulf; it is where occupants spend most of their time, entertain and welcome visitors. Al-Majlis occupants usually sit on the ground level as traditions mandate in the region. Due to its importance, thermal comfort of the occupants in such spaces is crucial and should be critically studied.

As any other living space, Al-Majlis requires a visual sight to the outdoor environment, which is reflected by a Window-to-Wall Ratio (WWR) of at least 30\%. As the glazed surfaces are known to be the weakest component of the building envelope, these windows typically cause significant solar transmission and absorption, eventually augmenting the space thermal energy demands and damaging its occupants' thermal comfort [5, 6].

Recently, solutions to thermal discomfort in outdoor environments have been proposed through the use of jackets filled with Phase-Change Materials (PCM). These jackets were found to mitigate the workers' thermal stresses significantly, even in harsh weather conditions [7-9]. However, the applicability of such techniques is troubled in indoor spaces. In other words, the occupants of the living space would not prefer moderating their thermal discomfort through wearing such jackets at home.

Alternatively, techniques applied to the space outdoor envelope have been proposed to decrease its energy consumption and simultaneously enhance the occupants' thermal comfort. These techniques include the design of a solar chimney integrated with passive evaporative cooler and applied on windows [10], the installation of shading devices [11, 12], the adoption of shading and lighting control strategies $[13,14]$ and the change in the air-distribution system [15]. However, all of these methods are never suitable in all cases; they are inapplicable in humid conditions, sacrifice the visual comfort of the occupants by blocking their sight to outside, and are sometimes extremely expensive to adopt.

Instead of modifying the space outer envelope, changes in the inner envelope have been alternatively suggested. For instance, tiles covering the indoor floor surface were proven to mitigate hot thermal sensations and enhance the occupants' comfort level. To further expand their effect, Phase Change Materials (PCM) was added to these floor tiles. The addition of PCM absorbs 
the heat coming through the floor during the daytime and releases it at night. Hence, it reduces the peak convective heat load dissipated from the floor and shifts it to a later time of the day. Several studies have been carried out in order to analyze the effect of PCM-enhanced floor tiles on thermal comfort and energy consumption in cold climates [16, 17]. It was found that these tiles do enhance thermal comfort, yet they have a little effect of less than $4 \%$ in reducing the heating demand. Nonetheless, little research was found on their application in coolingdominated regions.

In this study, the effect of adding PCM-enhanced tiles on an energy-efficient Al-Majlis living space during one summer representative day is investigated in terms of thermal comfort and space thermal cooling energy demand in the hot climate of Doha, Qatar. The selected city is a representative location of the Arabian Gulf, as the entire area suffers from harshly hot weather conditions.

\section{Methodology}

\subsection{Al-Majlis living space}

Before providing detailed description on the selected Majlis, it is important to point out that the space carried out herein takes into account several energy-efficient measures, which have become popular in Qatar. Hence, any further energy reductions are considered beneficial considering the tight building envelope and selected construction practices.

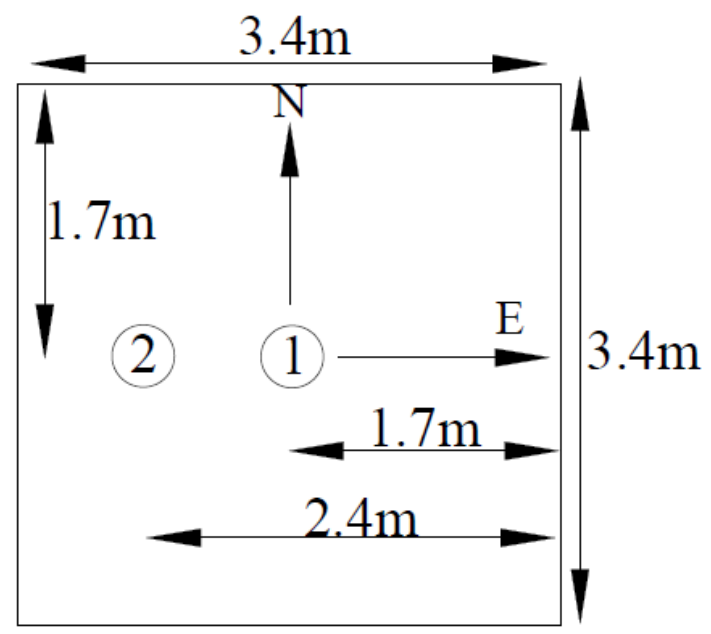

Fig. 1. Schematic representing Al-Majlis dimensions and occupants' positions inside the space.

A typical Majlis living space is picked in this study. As shown in Fig. 1, the space has a floor area of $11.56 \mathrm{~m}^{2}$ and a height of $2.6 \mathrm{~m}$ [15]. The Majlis is assumed to be exposed to the outside environment from all sides except from the west surface, which is adjacent to other conditioned spaces of the residential building. The space has two windows with dimensions of $2.2 \mathrm{~m} \times 1.2 \mathrm{~m}$ in each of the north and east-oriented walls (window-to- wall ratio of 30\%), as these surface directions are known to be hit by relatively less solar radiation intensities throughout the year in comparison with other orientations. The layer-by-layer detailed description of the building envelope, from outside to inside, along with each surface overall heat transfer coefficient (U-value) are reported in Table 1. The selected building envelope has been chosen in according with actual construction practices in the country.

Table 1. Al-majlis thermal envelope selected for this study.

\begin{tabular}{|c|c|c|}
\hline Surface & Specification & $\begin{array}{l}\text { U-value } \\
\left(\mathrm{W} / \mathrm{m}^{2} \cdot \mathrm{K}\right)\end{array}$ \\
\hline Wall & $\begin{array}{l}\text { 2cm Stucco }-20 \mathrm{~cm} \text { Concrete Heavy } \\
\text { Weight }-5 \mathrm{~mm} \text { Polyurethane Insulation } \\
-32 \mathrm{~mm} \text { Gypsum board }\end{array}$ & 2.37 \\
\hline $\begin{array}{l}\text { Floor / } \\
\text { Ceiling }\end{array}$ & 150mm Concrete Light Weight & 3.81 \\
\hline Window & $\begin{array}{l}\text { 6mm Float Glass - 16mm Clearance - } \\
6 \mathrm{~mm} \text { Float Glass }\end{array}$ & 1.1 \\
\hline
\end{tabular}

Note that the external walls already include a thin insulation layer, which has been more frequently used in Qatar due to the raised awareness for more reduced energy-consuming buildings. Also, note that the window clearance contains $10 \%$ air and $90 \%$ argon, and the window itself is extremely energy-efficient (SHGC = 0.16 ) as it has been specifically designed by SAPA for usage in residential buildings in Qatar. Detailed properties of the window are found in [13].

Two representative occupants were picked to analyse their thermal comfort responses. As seen in Fig. 1, the first is located in the middle of the room (i.e. at the position that would be least affected by the addition of tiles as it is the farthest from the wall surfaces) whereas the second is positioned one meter away from the west surface (i.e. closer to a surface with PCM-enhanced tiles).

\subsection{Simulation model}

\subsubsection{EnergyPlus Model}

In order to study the thermal performance of the living space and select a thermal comfort model, energy simulation software was deemed necessary. EnergyPlus version 8.5 was selected for this purpose [18]. This software has shown its capability in performing accurate energy analysis using the heat balance method, which is selected by ASHRAE for estimating the buildings' thermal performances [19].

A simulation model of Al-Majlis space was designed on EnergyPlus; all the walls were set to face the outdoor environment with direct sun and wind exposure except for the west wall. This surface was set to adiabatic conditions, as recommended by the software documentation for internal surfaces between zones showing little to no great temperature differences [20].

Once the PCM-enhanced tiles are added to the space, they covered the floor/wall as two additional material layers. They were selected to cover the entire floor area and up to a height of $0.6 \mathrm{~m}$ of the vertical walls surface areas. This distance was chosen because, as per ASHRAE guidelines, a height of $0.6 \mathrm{~m}$ should be used to $\square$ nalyse 
the thermal comfort of seated occupants [21]. Hence, a new wall was designed and contained the two additional layers while keeping the original wall as is; the first covered the lower part of the space while the latter covered its upper part. The selected PCM was paraffin that has a melting temperature of $30^{\circ} \mathrm{C}$ [17].

It is of interest to mention that the ConductionFiniteDifference heat balance algorithm was used instead of the normal ConductionTransferFunction due to its capability in modelling phase change materials, as recommended by EnergyPlus [20]. In addition, the IdealLoadAirSystem was used to predict the space thermal cooling energy demands without having to select or design a specific air-conditioning system [20]. The allday indoor set-point temperature was $24^{\circ} \mathrm{C}$. Lastly, the simulation model was set to run for several cycles in order to eliminate the effect of initial conditions.

\subsubsection{Thermal comfort model}

The thermal comfort of space occupants is of extreme importance and usually depends on several factors, such as the air temperature, humidity and velocity, as well as the space mean radiant temperature, operative temperature and radiant temperature asymmetry [22]. Using these ambient parameters, the Predictive Mean Vote (PMV) is calculated to predict the human thermal sensation. This PMV parameter, and consequently the Predicted Percentage of Dissatisfied (PPD) people, was originally presented by Fanger for the evaluation of thermal environments [23]. Among the different built-in thermal comfort models available on EnergyPlus, Fanger model was selected.

In this model, the human thermal sensation, and consequently its thermal comfort, is related to the body as a whole. In other words, the exact sensation at a specific part of the body is not determined as it requires another segmental body model [10]. This selected Fanger model is applicable in uniform thermal environments where the air ambient parameters (i.e. temperature, humidity, velocity...) do not vary inside the space. In addition, this model is valid in quasi-steady state conditions when the temporal gradient of the parameters affecting thermal comfort do not vary significantly from one time-step to another. Based on the prepared simulation model, all the aforementioned conditions are met.

In order to exclude factors that may affect thermal comfort, the human activity was fixed to a metabolic rate of 1 Met (108W) belonging to seated occupants [21], the clothing was set to DynamicClothingModelASHRAE55 which fixes the clothing insulation for one day depending on the outdoor conditions [20], and the air velocity inside the space was set to $0.1 \mathrm{~m} / \mathrm{s}$. Note that the air velocity has a significant effect on the human thermal sensation as moving air, up to a certain point, enhances comfort even at higher space temperatures. For this reason, a conservative value was selected. The rest of the parameter are those affected by the addition of tiles to the space inner envelope and are analyzed through the space mean radiant temperature, operative temperature, PMV and PPD.
In the developed simulation model, the Mean Radiant Temperature (MRT) is calculated using the anglefactor method; the view factor between the occupant and each surface, which are calculated by the authors according to ASHRAE [21], are inputted one by one. In comparison with other built-in methods, this method is more accurate as it uses the exact view factor between the occupant and each surface, and weighs their surface temperatures based on that factor according to Equation 1 [20].

$$
M R T=\sum F_{\text {Occupant-Surface }} \times T_{\text {Surface }}
$$

Similarly, the Operative Temperature (OT) is another indicator of thermal enhancement that combines the MRT with the zone temperature, and is analyzed as well in this study. For air velocities of equal or less than $0.1 \mathrm{~m} / \mathrm{s}$, the operative temperature can be simplified and calculated according to Equation 2:

$$
O T=\frac{T_{\text {Zone }}+M R T}{2}
$$

According to Fanger, the PMV is a subjective thermal sensation that ranges between -3 and 3 representing very cold and hot sensations, respectively. This parameter is used to assess the human thermal response in comparison with the ideal value of zero that represents thermal neutrality. Hence, the closer the PMV is to the range of 0.5 to 0.5 , the better the thermal comfort is. However, since the PMV is a subjective response, it is often combined with the PPD that estimates the percentage of people dissatisfied by the predetermined thermal sensation. Thus, these four parameters are selected to analyze the enhancement in thermal comfort due to the addition of PCM-enhanced tiles. Lastly, the space cooling thermal energy demand is investigated before and after the addition of the tiles to look for potential energy savings.

\subsection{Summer representative day}

In order to analyze the hourly response of the developed simulation model in hot weather conditions, one representative summer day was picked. July $21^{\text {st }}$ was selected where the hourly temperature, relative humidity and beam and diffuse solar radiations data were extracted from the Doha weather file recorded for the year of 2015 [24]. The outdoor temperature during this day ranged between $32.8^{\circ} \mathrm{C}$ and $43.0^{\circ} \mathrm{C}$ whereas the outdoor relative humidity varied between $9 \%$ and $67 \%$. On the other hand, the direct and diffuse solar radiations peaked to $841 \mathrm{~W} / \mathrm{m}^{2}$ and $182 \mathrm{~W} / \mathrm{m}^{2}$, respectively. In the developed model, one SummerDesignDay option was selected for the simulation where the variations in the aforementioned outdoor weather parameters were inputted as hourly profiles.

\section{Results and discussion}

Before going deeper in the results analysis, it is of interest to mention that, analytically speaking, the addition of PCM-enhanced tiles on portions of the walls splits each of them into two. According to Equation 1, the number of vertical walls is doubled and the new view 
factors between the occupant and each of them is recalculated. More importantly, the view factor between the occupant and the lower portion of the walls where tiles are added is significant, despite their smaller surface areas in comparison with the upper original walls.

Since the occupant activity and clothing as well as the air velocity inside the space were fixed, any changes in the human thermal comfort would be caused solely by the addition of the PCM-enhanced tiles. These tiles will have an inner space surface temperature that is different from those of the walls and, due to angle factor between them and the occupant, will unarguably affect his thermal response. The hourly mean radiant temperature (MRT), operative temperature (OT), PMV and PPD with and without the addition of PCM-enhanced tiles for both occupants are plotted in Figs. 2 and 3.

\subsection{Occupant 1}

In the base-case (i.e. before the installation of tiles), the MRT ranged between $27.6^{\circ} \mathrm{C}$ at 5 hours and $34.7^{\circ} \mathrm{C}$ at 15 hours. This trend shrank to range between $28.3^{\circ} \mathrm{C}$ and $34.0^{\circ} \mathrm{C}$ when the tiles were added, as shown in Fig. 2(a). In other words, the addition of the tiles reduced the MRT in the times between 6 hours and 21 hours and increased it slightly during the rest of the day. As anticipated, the addition of tiles with PCM on their back reduces the inner surface temperatures of the walls, eventually dropping the MRT. Consequently, the convective heat load from these surfaces is reduced as heat gain is being absorbed by the PCM. However, during the early and later times of the day, the PCM releases the pre-absorbed heat to the indoor space, thus increasing the tile surface temperature and eventually the MRT.

Based on the definition of the operative temperature represented in Equation 2, and considering that the zone air temperature is fixed, the changes in MRT affected the OT analogously. Yet, the changes in OT are smoother; it varies between $25.7^{\circ} \mathrm{C}$ and $29.4^{\circ} \mathrm{C}$ before the addition of tiles and between $26.1^{\circ} \mathrm{C}$ and $29.0^{\circ} \mathrm{C}$ after their addition (refer to Fig. 2(b)).

As seen in Fig. 2(c), the changes in PMV were analogous to those of the MRT and OT. Before the addition of tiles, PMV increased during the daytime, reached a value of 1.0 at 15 hours and decreased back down for the rest of the day. Recall that a PMV of zero represents thermal neutrality and a value greater than 0.5 represents thermal discomfort caused by hot sensations. In this case, this condition was always violated during the hours between 9 and 20 hours. This led a dissatisfaction percentage as high as $26.2 \%$, as shown in Fig. 2(d). However, since the addition of the tiles decreased the MRT and OT, it reduced the PMV during most of the hours of the day. Although its peak value is 0.9 , the PMV values were moderated throughout the day and became always closer the PMV recommended limit. This moderation led to a decline in the percentage of dissatisfaction whose peak value went down to $21.6 \%$.

Note that an improvement in thermal response is noticed during most of the hours when the living space is expected to be occupied. In early hours of the morning and late hours of the day, during which the space is not expected to be occupied, PMV values increased, yet never violated the 0.5 limit.
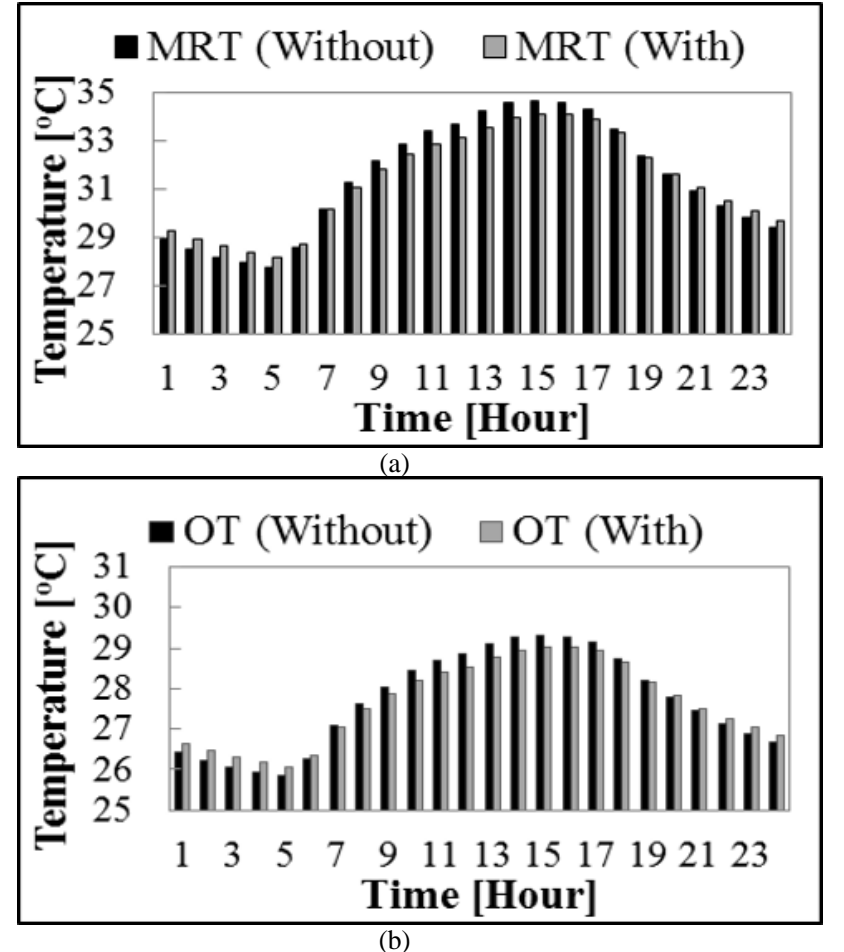

(b)
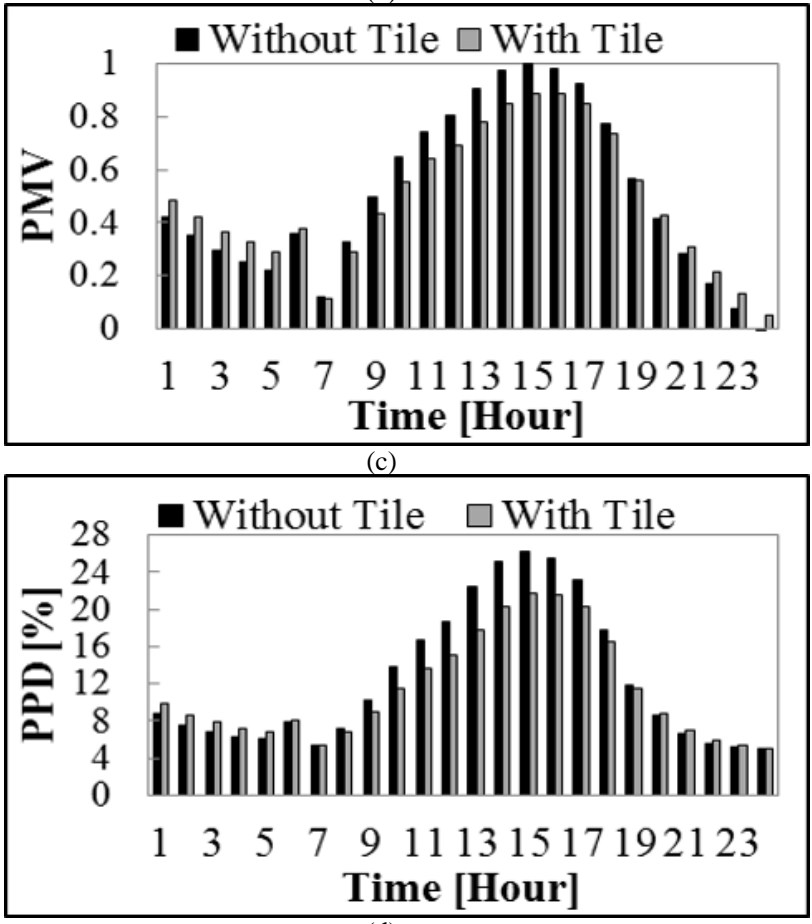

(d)

Fig. 2. Hourly results of (a) Mean Radiant Temperature (MRT), (b) Operative Temperature (OT), (c) Predicted Mean Vote (PMV) and Predicted Percentage of Dissatisfied (PPD) for Occupants 1 and 2.

\subsection{Occupant 2}

The results pertinent to the second occupant are comparable to the first one. Yet, since this occupant is seated closer to the west surface with PCM-enhanced tiles (i.e. farther away from the north and east windows), 
the benefits of the changes in the indoor envelope are amplified. For instance, and in contrast with the first occupant, the MRT and OT at the second occupant's location decreased throughout the entire period with almost no counter-effects during the late hours of the day, as seen in Figs. 3(a)-(b).
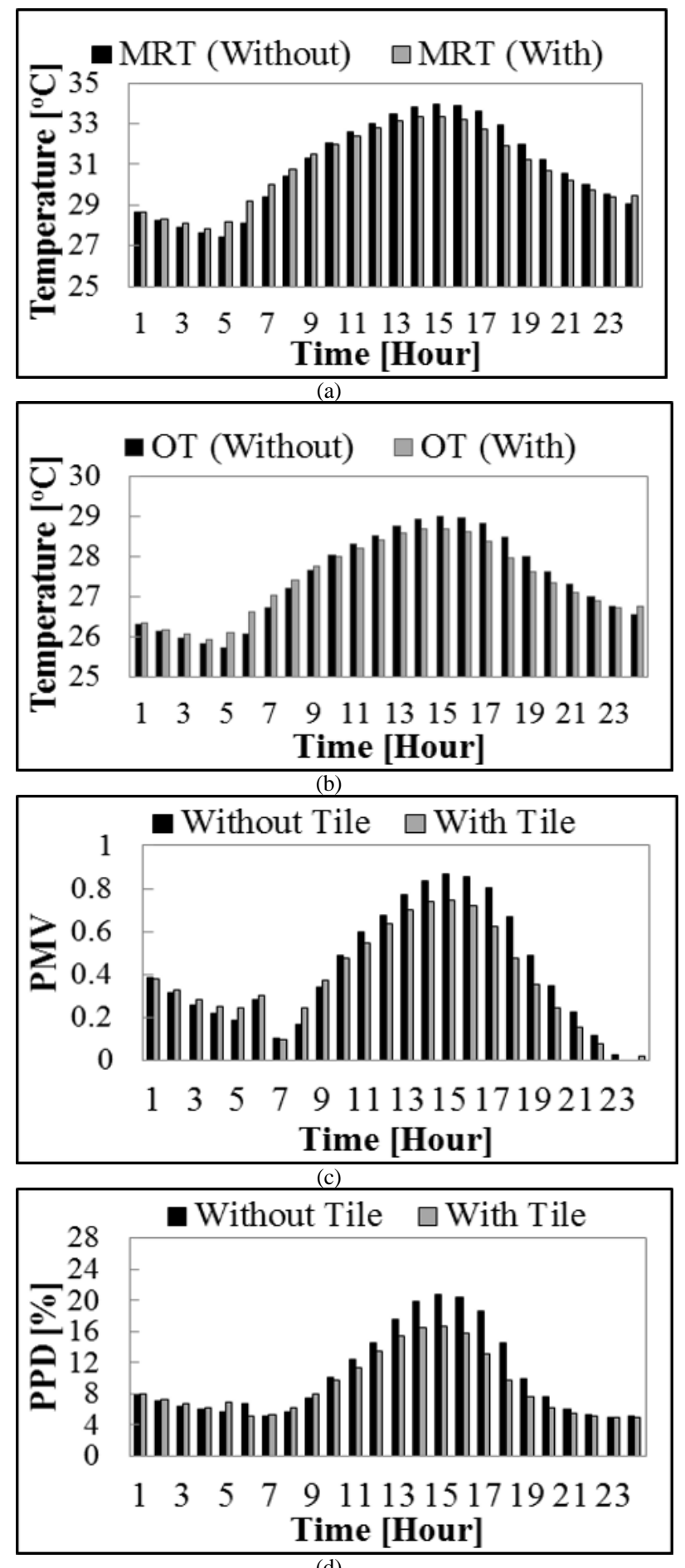

(d)

Fig. 3. Hourly results of (a) Mean Radiant Temperature (MRT), (b) Operative Temperature (OT), (c) Predicted Mean Vote (PMV) and Predicted Percentage of Dissatisfied (PPD) for Occupants 1 and 2.
Consequently, these results affected the PMV and PPD analogously. Due to this occupant's larger angle factor with the west surface, which is more moderate than the rest of the space surfaces, his PMV trend shifted down to become closer to the 0.5 proposed limit (refer to Fig. 3(c)) and consequently the PPD decreased simultaneously. In fact, the peak PPD decreased from $20.8 \%$ to $16.6 \%$, as shown in Fig. 3(d).

Since the position of the second occupant is more realistic in living spaces, the addition of the PCMenhanced tiles to portions of the space indoor surfaces is analytically justified as it enhances thermal comfort whenever the space is expected to be occupied.

\subsection{Energy savings}

Lastly, it would be important to mention that the space daily cooling thermal energy demand before and after the installation of PCM-enhanced tiles decreased from 30.6 $\mathrm{kWh}$ to $29.6 \mathrm{kWh}$. Although it is a slight reduction, the addition of these tiles ended up saving $3.3 \%$ of the space cooling demand.

\section{Conclusion}

Due to the importance of human thermal comfort in living spaces, or the so-called Al-Majlis in the Arabian Gulf, the changes in occupant thermal response and space cooling energy demand caused by the addition PCMenhanced tiles was investigated. These tiles were selected to cover the entire floor area as well as portions of the vertical walls surface area from the ground level up to a height of 0.6 meters. This distance was chosen as it represents the typical height of a seated person as per ASHRHAE guidelines.

A simulation model of a Majlis space was developed; it considers a tight building envelope containing insulations layers and efficient glazing systems, and two occupants seated differently inside the space. Results have shown that the addition of PCM-enhanced tiles was able to moderate the mean radiant temperature and operative temperature. Consequently, the PMV and PPD trends shrank. During the hour times when the living space is expected to be occupied, the addition of tiles shifted the PMV closer to the comfort range and was found to save $3.3 \%$ of the space daily cooling energy demand during one harshly hot summer day in Doha, Qatar. Should the same analysis be conducted on another, less tight living space, energy savings would be intensified. Similarly, the improvement in human thermal comfort is expected to amplify whenever these tiles cover larger portions of the vertical walls or when the original thermal discomfort is greater due to larger glazing surfaces.

\section{Acknowledgment}

This publication was made possible by NPRP $7-486-2-185$ from the Qatar National Research Fund (a member of Qatar Foundation). The findings achieved herein are solely the responsibility of the authors. 


\section{References}

1. Petroleum, B. BP statistical review of world energy. (2017)

2. Ghiaus C, Inard C. Energy and environmental issues of smart buildings, A Handbook for Intelligent Building, 26-51 (2004)

3. Said, S. A. M., Habib, M. A., \& Iqbal, M. O., Database for building energy prediction in Saudi Arabia. Energy conversion and management, 44 (2003)

4. Ayoub, N., Musharavati, F., Pokharel, S., \& Gabbar, H. A, Energy consumption and conservation practices in Qatar-A case study of a hotel building. Energy and Buildings, 84 (2014)

5. Al Touma, A., Ghali, K., Ghaddar, N., \& Ismail, N., Solar chimney integrated with passive evaporative cooler applied on glazing surfaces. Energy, 115, (2016)

6. Al Touma, A., \& Ouahrani, D. Experimental analysis of double and triple glazed façades with different shading devices in Qatar. In Sustainable and Renewable Energy Engineering (ICSREE), 2017 2nd International Conference. IEEE. 38-41 (2017)

7. Hamdan, H., Ghaddar, N., Ouahrani, D., Ghali, K., \& Itani, M. PCM cooling vest for improving thermal comfort in hot environment. International Journal of Thermal Sciences, 102, 154-167 (2016)

8. Itani, M., Ouahrani, D., Ghaddar, N., Ghali, K., \& Chakroun, W. The effect of PCM placement on torso cooling vest for an active human in hot environment. Building and Environment, 107, 29-42 (2016)

9. Ouahrani, D., Itani, M., Ghaddar, N., Ghali, K., \& Khater, B. Experimental study on using PCMs of different melting temperatures in one cooling vest to reduce its weight and improve comfort. Energy and Buildings. (2017)

10. Hweij, W. A., Al Touma, A., Ghali, K., \& Ghaddar, N. Evaporatively-cooled window driven by solar chimney to improve energy efficiency and thermal comfort in dry desert climate. Energy and Buildings, 139, 755-761, (2017)

11. Li, C., Tan, J., Chow, T. T., \& Qiu, Z. Experimental and theoretical study on the effect of window films on building energy consumption. Energy and Buildings, 102, 129-138, (2015)

12. Li, D. H., Lam, T. N., Wong, S. L., \& Tsang, E. K. Lighting and cooling energy consumption in an open-plan office using solar film coating. Energy, 33 1288-1297 (2008)

13. Al Touma, A., \& Ouahrani, D. Shading and daylighting controls energy savings in offices with fullyGlazed façades in hot climates. Energy and Buildings, 151, 263-274 (2017)

14. Lee, K. H., Kim, T., Lee, G., \& Lee, J. Cooling load reduction effect and its mechanism in between-glass cavity and venetian blind operation during the summer season. In Building Simulation. Springer Berlin Heidelberg. 6, 351-364 (2013)

15. Hweij, W. A., Ghaddar, N., Ghali, K., \& Habchi, C. Optimized performance of displacement ventilation aided with chair fans for comfort and indoor air quality. Energy and Buildings, 127, 907-919 (2016)

16. Barbour, J. P., \& Hittle, D. C. Modeling phase change materials with conduction transfer functions for passive solar applications. Journal of solar energy engineering, 128, 58-68 (2006)

17. Stamatiadou, M., Antonopoulos, K., \& Founti, M.. Energy savings using floor tiles with phase change materials in a S. European country. In Proceedings of 11th international conference on thermal energy storage; Effstock. (2009)

18. U.S. Department of Energy, EnergyPlus Energy Simulation Software. http://apps1.eere.energy.gov/buildings/energyplus. (2013)

19. ASHRAE, Chapter 19 energy estimating and modeling methods, in: ASHRAE Fundamentals Handbook, American Society of Heating, Refrigerating and Air-Conditioning Engineers., Atlanta, USA, (2009)

20. E. Doe, 6.0 Input/Output Reference: The Encyclopedic Reference to EnergyPlus Input and Output, US Department of Energy., (2010)

21. Standard, A. S. H. R. A. E. Standard 552010:"Thermal Environmental Conditions for Human Occupancy”; ASHRAE. Atlanta USA. (2010)

22. McQuiston, F. C., \& Parker, J. D. Heating, ventilating, and air conditioning: analysis and design. (1982)

23. Fanger, P. O. Thermal comfort. Analysis and applications in environmental engineering. (1970)

24. Online Resource, http://weather.whiteboxtechnologies.com. 